\title{
The Use of Glutamic Acid as Corrosion Inhibitor for Aluminium in Hcl Solution
}

\author{
* Ayuba Abdullahi Muhammad, ${ }^{2}$ Adamu Uzairu, ${ }^{2}$ J. F. Iyun, ${ }^{2}$ Hamza Abba \\ ${ }^{I}$ (Department of Pure and Industrial Chemistry, Bayero University, Kano, Nigeria) \\ 2 (Department of Chemistry, Ahmadu Bello University, Zaria, Nigeria)
}

\begin{abstract}
The adsorptive and inhibitive action of glutamic acid towards general and pitting corrosion of aluminium in $\mathrm{HCl}$ solution was investigated using weight loss, gasometric and thermometric methods. Glutamic acid was found to inhibit the corrosion of aluminium in $\mathrm{HCl}$ solution. The inhibition efficiency of glutamic acid decreased with increase in temperature, period of immersion and $\mathrm{HCl}$ concentration, but increased with increasing glutamic acid concentration. Adsorption characteristics of glutamic acid have also been studied and it was found that the process obeys physical adsorption. Thermodynamic parameters including; $E_{a}, Q_{a d s}, \Delta S_{a d s}$, $\Delta H_{\text {ads }}$ and $\Delta G_{\text {ads }}$ for the adsorption process signifies a spontaneous process. While Langmuir, Frumkin, FloryHuggins and El-Awardy isotherm adsorption models can be used to explain the mechanism of glutamic acid adsorption onto aluminium surface in $\mathrm{HCl}$ solution.
\end{abstract}

Key words: Aluminium, Corrosion, Glutamic Acid, Physical adsorption, Spontaneous

\section{Introduction}

Aluminium and its alloys exhibit corrosion resistance in varied environments and have many important applications. The manifestation of its corrosion resistance in different aggressive media has continued to generate lots of interest. In aqueous solution, aluminium generally exhibits passive behaviour which influences its corrosion susceptibility. The adhesive passivating surface oxide film is amphoteric and consequently the metal dissolves readily in acidic and basic solutions [1]. Corrosion of aluminium and its alloys has been a subject of numerous studies due to their high technological value and wide range of industrial applications especially in aerospace and household industries. Aluminium and its alloys, however, are reactive materials and are prone to corrosion [2]. The most frequently applied protection of aluminium and its alloys involves the use of chromates either in various organic coatings or for the production of chemical conversion coatings. The environmental and health risks however associated with the use of chromates have imposed pressure towards finding effective alternative solutions. Encouraging results have been obtained by using rare earth metals and organic compounds containing carboxylic groups. The organic compounds act in a different manner than the metal ions which are believed to be incorporated into the protective oxide layer on the aluminium surface. The organic compounds possessing ionisable groups as is the case with the carboxylic acids may interact electrostatically with the metal, alloy and/or the oxide surface possibly through formation of surface complexes which may in turn affect the rate and the extent of the oxide formation [3]. Adsorption characteristics of these inhibitors depend on several factors including the nature and number of potential adsorption sites present in the inhibitor molecule. Numerous attempts are made to link the corrosion inhibitor efficiency with a number of structural parameters of these molecules [3].

In many cases the parameters connected with the electronic and the chemical structure of the molecule act simultaneously on the inhibitor efficiency and it is difficult to decide which parameter plays the most important role in increasing the inhibitor efficiency [2]. Many researchers have used such organic compounds to inhibit the corrosion of aluminium or its alloys $[1,2,3,4,5]$. It is within the scope of this research to use and establish the adsorptive and inhibitive properties of Glutamic acid on the corrosion of aluminium in $\mathrm{HCl}$ media using various methods.

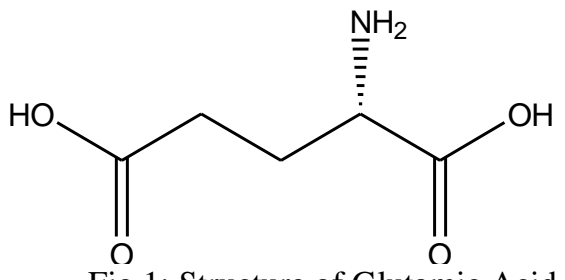

Fig 1: Structure of Glutamic Acid 


\subsection{Materials}

\section{Materials and Methods}

The material used for the study is aluminium sheet of composition (wt\%): $\mathrm{Al}(98.70), \mathrm{Si}(0.48)$, $\mathrm{Cl}(0.014), \mathrm{K}(0.04), \mathrm{Ca}(0.01), \mathrm{Ti}(0.005), \mathrm{V}(0.016), \mathrm{Mn}(0.012), \mathrm{Fe}(0.50), \mathrm{Ni}(0.013), \mathrm{Cu}(0.048), \mathrm{Ga}(0.013)$, $\operatorname{In}(0.10), \operatorname{Te}(0.010), \mathrm{Ba}(0.009), \operatorname{Os}(0.032), \operatorname{Ir}(0.03)$. The sheet was mechanically pressed-cut into different coupons, each of dimension $5 \times 4 \times 0.11 \mathrm{~cm}$. Each coupon was degreased by washing with ethanol, dipped in acetone and allowed to dry in air before they were preserved in a desiccator. All reagents used for the study were Analar grade and double distilled water was used for their preparation.

The inhibitor (Glutamic acid) was supplied by CEMAN Pharmaceutical Company, Kano State, Nigeria, and was used without further purification. The range for the concentrations of the inhibitor used for the study was $4.0 \times 10^{-4}$ to $20 \times 10^{-4} \mathrm{M}$. Each of these concentrations was dissolved in 0.2, 0.4, 0.6, 0.8 and 1.0M $\mathrm{HCl}$ for use in weight loss, gasometric and thermometric methods respectively.

\subsection{Methods}

\subsubsection{Weight Loss method}

In the weight loss experiment, a previously weighed metal (aluminium) coupon was completely immersed in $250 \mathrm{~cm}^{3}$ of the test solution in an open beaker. The beaker was covered and inserted into a water bath maintained at $303 \mathrm{~K}$. After every 24 hours, each coupon was withdrawn from the test solution, washed in a solution containing $50 \% \mathrm{NaOH}$ and $100 \mathrm{gL}^{-1}$ of zinc dust (in order to remove the corrosion product). The washed aluminium coupon was rinsed in acetone and dried in air and the weight difference recorded. The difference in weight for a period of 168 hours was taken as total weight loss. The experiments were repeated at 313 and $323 \mathrm{~K}$ respectively. From the weight loss results, the degree of surface coverage $(\theta)$, inhibition efficiency (\% I) of the inhibitor and corrosion rates $\left(\mathrm{CR}\right.$ in $\left.\mathrm{gh}^{-1} \mathrm{~cm}^{-2}\right)$ were calculated using Equations (1), (2) and (3) below:

$$
\begin{aligned}
& \vartheta=1-\frac{W_{1}}{W_{2}} \\
& \% I=\left(1-\frac{W_{1}}{W_{2}}\right) \times 100 \\
& C R\left(\mathrm{gh}^{-1} \mathrm{~cm}^{-2}\right)=\frac{\Delta W}{A t}
\end{aligned}
$$

where $\mathrm{W}_{1}$ and $\mathrm{W}_{2}$ are the weight losses ( $\mathrm{g}$ ) for aluminium in the presence and absence of the inhibitor in $\mathrm{HCl}$ solution, $\theta$ is the degree of surface coverage of the inhibitor, $\mathrm{A}$ is the area of the aluminium coupon (in $\mathrm{cm}^{2}$ ), $\mathrm{t}$ is the period of immersion (in hours) and $\Delta \mathrm{W}$ is the weight loss of mild steel after time, $\mathrm{t}[6,7,8,9]$.

\subsubsection{Gasometric method}

Gasometric methods were carried out at 303,313 and $323 \mathrm{~K}$ as described in the literature $[6,7,8,9]$. From the volume of hydrogen gas evolved per minute, surface coverage $(\theta)$, inhibition efficiencies $(\% \mathrm{I})$ and corrosion rate were calculated using Equations (4), (5) and (6):

$$
\begin{aligned}
& \% I=\left(1-\frac{V_{H t}^{\prime}}{V_{H t}^{o}}\right) \times 100 \\
& \vartheta=\frac{\% I}{100}=1-\frac{V_{H t}^{\prime}}{V_{H t}^{o}} \\
& C R\left(\mathrm{~cm}^{3} \mathrm{~min}^{-1}\right)=\frac{V_{H t}^{\prime}}{t}
\end{aligned}
$$

where $\mathrm{V}_{\mathrm{Ht}}^{1}$ and $\mathrm{V}_{\mathrm{Ht}}^{0}$ are the volumes of $\mathrm{H}_{2}$ gas evolved at time $\mathrm{t}$ for inhibited and uninhibited solutions, respectively.

\subsubsection{Thermometric method}

The reaction vessel is a three-necked round bottom flask and the procedure for determining the corrosion behaviour by this method was described elsewhere by other authors [10,11,12]. The flask was well lagged to prevent heat losses. In this technique the corrodent $(\mathrm{HCl})$ concentration was also varied at $0.2,0.4,0.6$, 0.8 and $1.0 \mathrm{M}$ respectively. The volume of the test solution used was $100 \mathrm{~cm}^{3}$. The initial temperature in all the experiments was kept at room temperature. The progress of the corrosion reaction was monitored by determining the changes in temperature with time (each minute for the first five minutes, each five minutes for the next 25 minutes and each ten minutes for the last thirty minutes) using a calibrated thermometer $\left(0-100^{\circ} \mathrm{C}\right)$ to the nearest $\pm 0.05^{\circ} \mathrm{C}$. The data was generated for a period of one hour. This method enabled the computation of the reaction number (RN). From the rise in temperature of the system per minute, the reaction number (RN) was calculated using equation (7):

$$
R N\left({ }^{o} \mathrm{Cmin}^{-1}\right)=\frac{T_{m}-T_{i}}{t}
$$


Where $T_{m}$ is the maximum temperature attained by the system, $T_{i}$ is the initial temperature and $t$ is the time required to reach the maximum temperature. From the above, the inhibition efficiency (\%I) of the used inhibitor was computed using equation (8):

$\% I=\frac{R N_{a q}-R N_{w i}}{R N_{a q}} \times 100$

where $\mathrm{RN}_{\mathrm{aq}}$ is the reaction number of aqueous acid in the absence of the inhibitor, and $\mathrm{RN}_{\mathrm{wi}}$ is the reaction number of aqueous acid in the presence of inhibitor.

\section{Results and Discussion}

The study on the corrosion inhibition of aluminium in $\mathrm{HCl}$ solution using glutamic acid as inhibitor was conducted using weight loss, gasometric and thermometric methods. The results of this study was either presented in graphical or tabular format as the case may be or discussed herewith.

\subsection{Weight Loss Results}

Weight loss experiments were conducted by varying the temperatures $(303,313,323 \mathrm{~K})$, corrodent $(\mathrm{HCl})$ concentration $(0.2,0.4,0.6,0.8$ and $1.0 \mathrm{M})$ and inhibitor (glutamic acid) concentrations $(0.0004,0.0008$, $0.0012,0.0016$ and $0.0020 \mathrm{M}$ ) to obtain the results presented below.

A plot of weight loss variation with time for the corrosion of aluminium in varying $\mathrm{HCl}$ concentrations without the inhibitor at $303 \mathrm{~K}$ temperature is as presented in Fig. 2. It was observed that the longer the time of aluminium coupon immersion in the test solution the higher the weight loss through corrosion. Secondly, higher corrodent concentrations resulted into higher weight loss resulting into a higher corrosion rate. The same experiment was conducted at 313 and $323 \mathrm{~K}$ temperatures with similar results obtained. Similar results were earlier reported by other authors $[2,13]$.

The effect of temperature on the corrosion system was tested at three different temperatures $(303,313$ and 323K) respectively. It can be observed from Fig. 3, the highest weight loss of aluminium was observed at $323 \mathrm{~K}$ for $0.20 \mathrm{M} \mathrm{HCl}$. The results obtained for $0.40,0.60,0.80$ and $1.0 \mathrm{M} \mathrm{HCl}$ solutions were similar to that of $0.20 \mathrm{M} \mathrm{HCl}$ (Figures not shown). Similarly as in the effect of corrodent concentration, higher temperatures produced higher weight loss with time, thus higher rate of reaction. Comparing the results at the five $\mathrm{HCl}$ concentrations, it is also evident that a combination of higher temperatures and corrodent concentrations produced respectively higher weight loss resulting into a higher corrosion rate. Therefore, the higher the temperature, the higher the rate of corrosion, suggesting a physical adsorption mechanism [2, 13].

To test and establish whether the inhibitor has an effect on the rate of aluminium corrosion in varying $\mathrm{HCl}$ solution, varying concentrations of the inhibitor was used. Fig. 4 presents the results of the effect of glutamic acid on the corrosion of aluminium in $0.20 \mathrm{M} \mathrm{HCl}$ solution at $303 \mathrm{~K}$. Similar results were obtained for $0.40,0.60,0.80$ and $1.0 \mathrm{M} \mathrm{HCl}$ and therefore were not presented even though with higher rate of reactions obtained. It reveals that the weight loss of aluminium in $\mathrm{HCl}$ increased with increase in the period of immersion but decreased with increase in the concentration of glutamic acid. This suggests that the rate of corrosion of aluminium in $\mathrm{HCl}$ increases with increase in the period of contact and decreases with increase in concentration of the inhibitor thereby decreasing the rate of corrosion reaction. At higher temperatures of 313 and $323 \mathrm{~K}$ (graphs not shown) weight loss were found to increase with increase in temperature even as the glutamic acid concentrations got higher, indicating that the rate of corrosion of aluminium in all $\mathrm{HCl}$ concentrations increases with increase in temperature and that glutamic acid is adsorbed on the surface of aluminium according to the mechanism of physical adsorption $[13,14,15]$.

To further establish whether corrodent $(\mathrm{HCl})$ concentration has an effect on the corrosion of aluminium in solution containing glutamic acid as inhibitor at varying temperatures, Fig. 5 revealed that the higher the concentration of the corrodent the higher the aluminium coupon weight loss resulting into a higher rate of reaction even in the presence of the inhibitor. But when such results were compared at different $\mathrm{HCl}$ concentrations it was observed that the rate of reaction decreases in the presence of the inhibitor when two systems were conducted at the same temperature and $\mathrm{HCl}$ concentrations. Similar results were also reported [1, $16,17]$. 

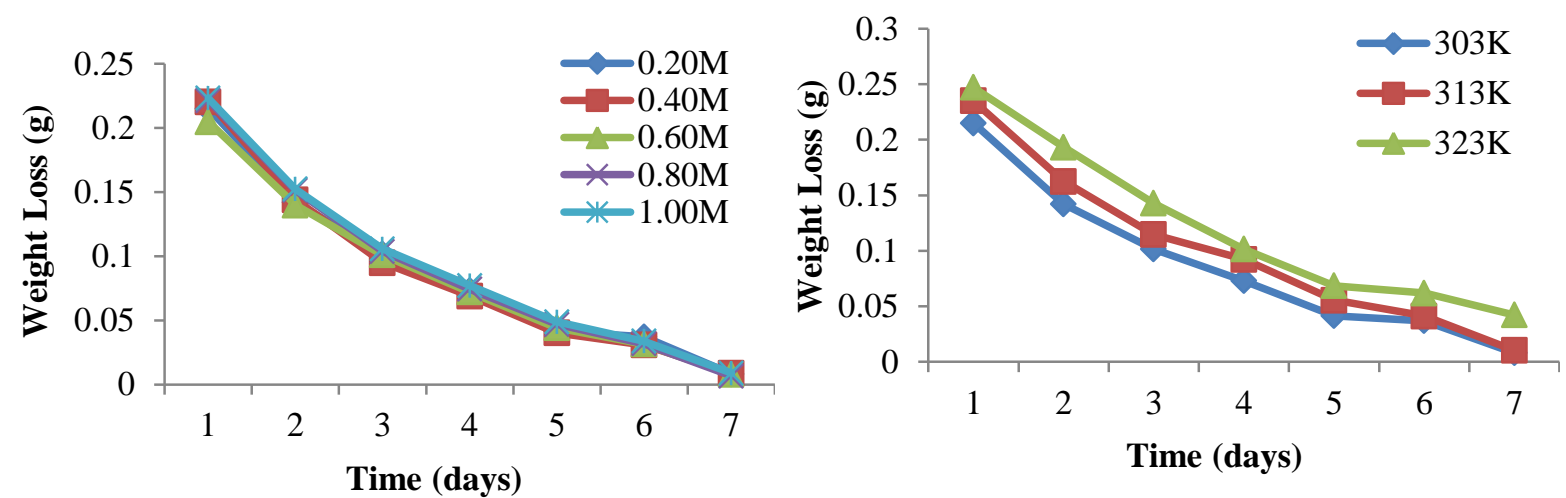

Fig 2: variation of weight loss with time for the corrosion of aluminium in varying $\mathrm{HCl}$ concentrations at $303 \mathrm{~K}$
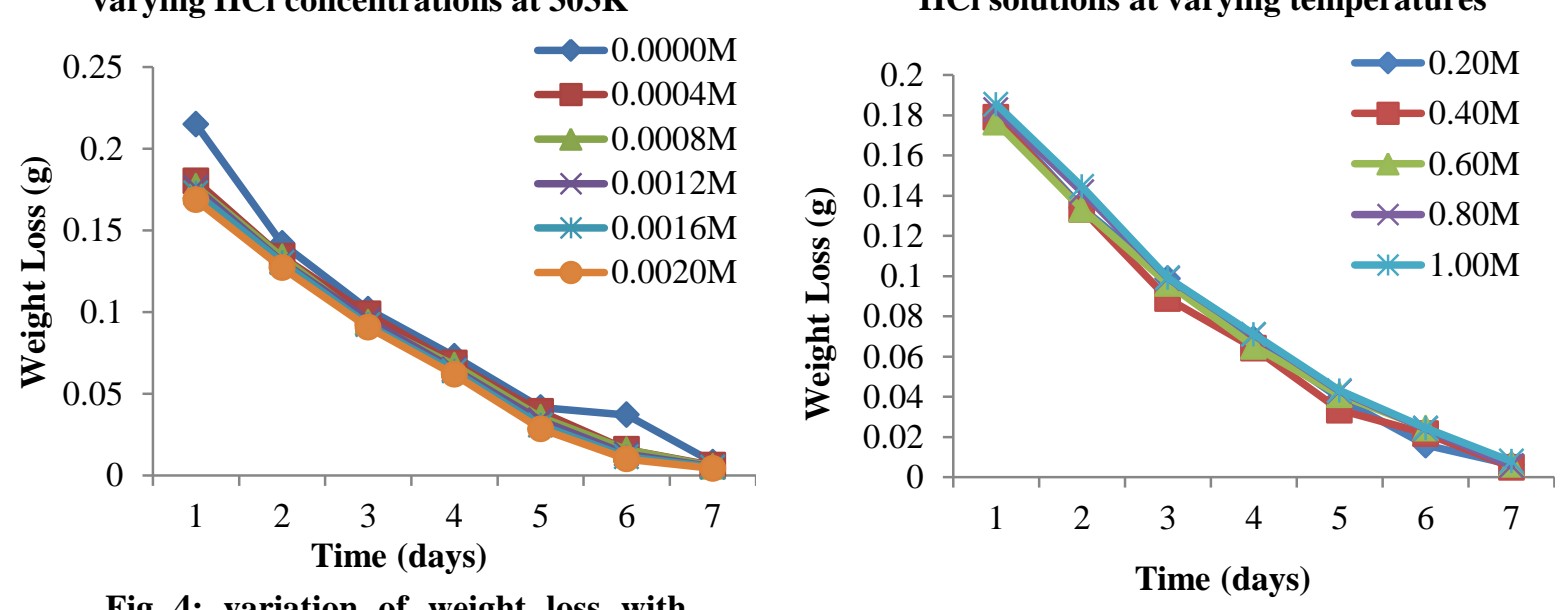

Fig 4: variation of weight loss with time for the corrosion of aluminium in 0.20M HCl containing varying concentrations of glutamic acid at 303K

Fig 3: variation of weight loss with time for the corrosion of aluminium in $0.20 \mathrm{M}$ $\mathrm{HCl}$ solutions at varying temperatures

Fig 5: variation of weight loss with time for the corrosion inhibition of aluminium using $0.0004 \mathrm{M}$ glutamic acid in various $\mathrm{HCl}$ solutions at $303 \mathrm{~K}$

\section{2 Gasometric Results}

The acidic corrosion of aluminium is characterised by evolution of hydrogen and the rate of corrosion is proportional to the amount of hydrogen gas evolved [18]. Gasometric experiments were carried out at 303, $313323 \mathrm{~K}$ respectively by varying the corrodent $(0.20,0.40,0.60 .0 .80$ and $1.0 \mathrm{M})$ and inhibitor concentrations ( 4 to $20 \times 10^{-4} \mathrm{M}$ ) respectively. From the volume of hydrogen gas evolved per minute, Figs. 6, 7, 8 and 9 resulted by plotting the volume of gas evolved against time in order to establish its corrosion rate.

It can be observed from Fig. 6 that the higher the corrodent concentration the higher the volume of gas evolved per minute at $303 \mathrm{~K}$. Similar results were obtained at higher temperatures of 313 and $323 \mathrm{~K}$ respectively. Fig. 7 presents the results of the effect of temperature variation in the absence of glutamic acid in $0.20 \mathrm{M} \mathrm{HCl}$ solution. It is evident that higher temperature of $323 \mathrm{~K}$ provided higher volume of hydrogen gas per minutes resulting into a higher rate of reaction. The same method was applied to $0.40,0.60,0.80$ and $1.0 \mathrm{M} \mathrm{HCl}$ concentrations with similar results obtained. Fig. 8 tried to establish the effect of glutamic acid in inhibiting aluminium corrosion in $0.20 \mathrm{M} \mathrm{HCl}$ at $303 \mathrm{~K}$. As the concentration of the inhibitor increases lower volume of hydrogen gas was evolved per minute. Similar results were obtained when $0.40,0.60,0.80$ and $1.0 \mathrm{M} \mathrm{HCl}$ at 313 and $323 \mathrm{~K}$ in the presence of glutamic acid systems were tested. To establish, regardless of temperature or corrodent concentration, the higher the volume of gas evolved per minutes the higher the rate of reaction (Fig. 9). Similar results were obtained from the weight loss experiments. It is also evident from the plots that there is an abrupt increase in the volume of hydrogen gas evolved after the first five minutes. This may be attributed to the reaction of the oxide layer with the $\mathrm{HCl}$ solution [19]. 


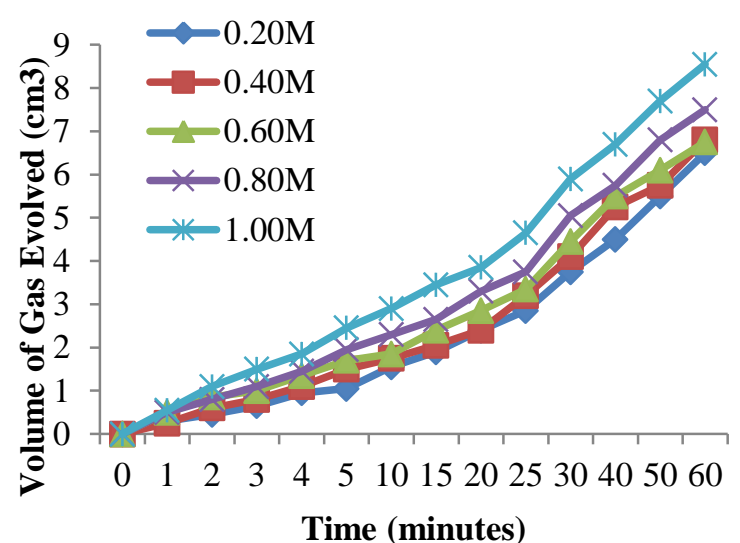

Fig 6: variation of the volume of hydrogen gas evolved with time for the corrosion of aluminium in varying $\mathrm{HCl}$ concentrations at $303 \mathrm{~K}$

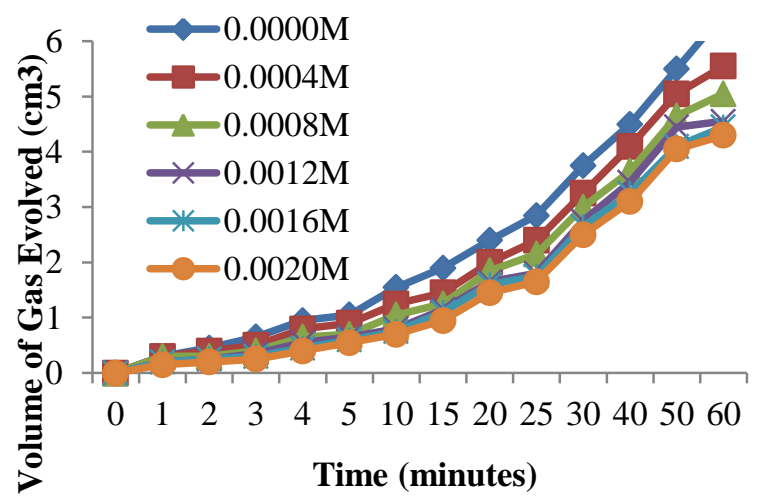

Fig 8: variation of the volume of hydrogen gas evolved with time for the corrosion of aluminium in $0.20 \mathrm{M} \mathrm{HCl}$ containing varying concentrations of glutamic acid at $303 K$

3.3 Thermometric Results

Thermometric methods were conducted by studying the effects of corrodent and inhibitor variation on the corrosion of aluminium at room temperature. Fig. 10 shows the variation of temperature with time for the corrosion of aluminium in varying $\mathrm{HCl}$ solutions. From the figure it can be seen that higher reaction temperatures were obtained as the concentration of $\mathrm{HCl}$ increases, suggesting an increase in corrosion rate. While in the presence of glutamic acid, the same trend of increase in reaction rate was observed as the concentration of $\mathrm{HCl}$ increases but the rate was comparably lower (Fig. 11). Thirdly, in trying to establish the inhibitive effect of varying concentration of glutamic acid in $\mathrm{HCl}$, it was observed from Fig. 12 that an increase in glutamic acid concentration decreases the reaction temperature and hence decreases the rate of reaction [8]. 


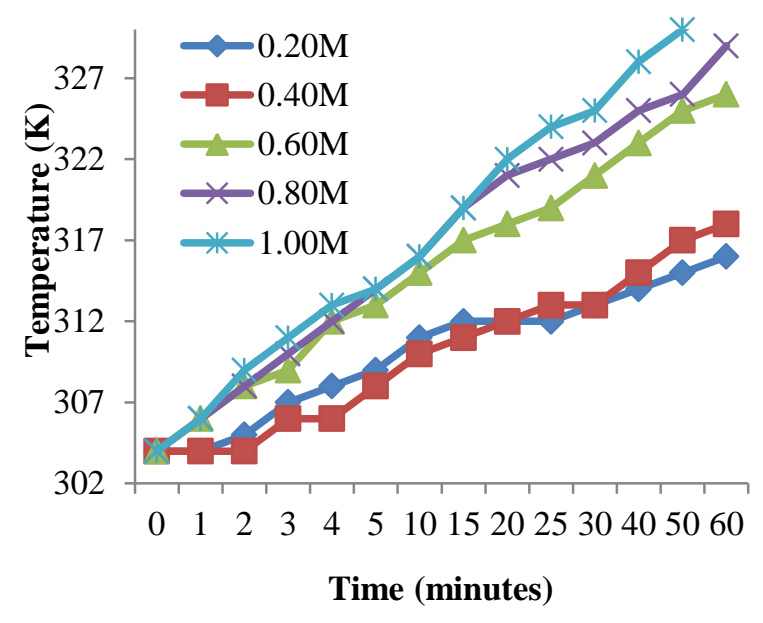

Fig 10: variation of temperature with time for the corrosion of aluminium in different $\mathrm{HCl}$ solutions

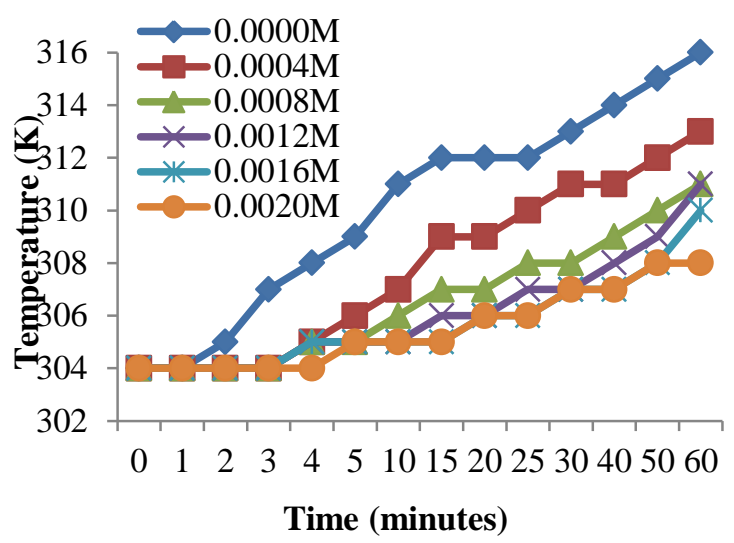

Fig 11: variation of temperature with time for the corrosion of aluminium in $0.20 \mathrm{M} H \mathrm{HCl}$ containing varying concentration of glutamic acid as inhibitor

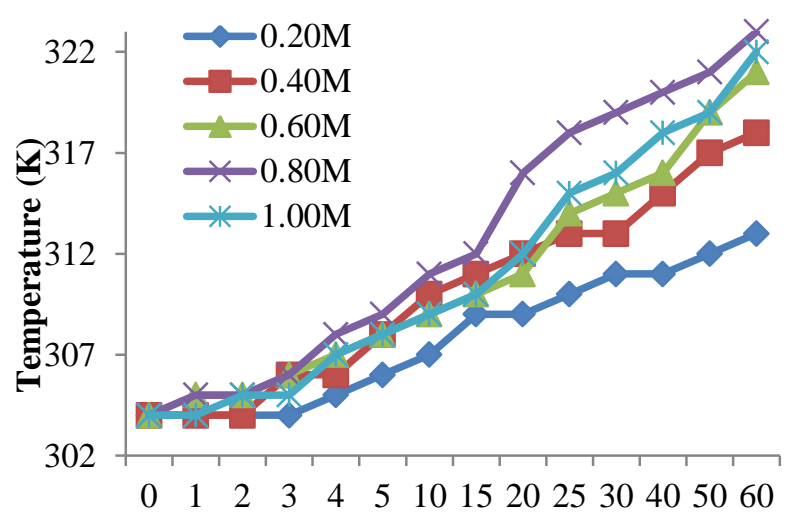

Time (minutes)

Fig 12: variation of temperature with time for the corrosion inhibition of aluminium using $0.0004 \mathrm{M}$ glutamic acid in various $\mathrm{HCl}$ solutions

\subsection{Kinetic Consideration}

It has been established by many researchers $[6,8,9,19]$ reported that most corrosion reactions obey the first order kinetic model. To further establish that with respect to the current study, equation (9) was used where $\mathrm{k}_{1}$ is the first order reaction rate constant and $\mathrm{t}$ is the time in days:

$$
-\log (\text { weight loss })=\frac{k_{1} t}{2.303}
$$

The plots of $-\log$ (weight loss) versus time (in the presence and absence of glutamic acid) were linear (with almost unity values for $\mathrm{R}^{2}$ ) confirming that a first order kinetic is applicable to the corrosion of aluminium in the presence and absence of glutamic acid. Also the half life of a first order reaction is related to the rate constant according to equation (10):

$t_{1 / 2}=\frac{0.693}{K_{1}}$

Values of the half life and rate constants obtained from the slopes of the kinetic plots are presented in the TABLE 1. The results revealed that the half lives of aluminium in the presence of glutamic acid were higher than those without glutamic acid indicating that the inhibitors increased the half life of aluminium in $\mathrm{HCl}$ solution. Secondly, it was also observed that the higher the glutamic acid concentration the higher the half life values. Thirdly, both temperature and $\mathrm{HCl}$ concentrations were found to affect the half life values, as can be seen from the TABLE 1, decrease in half lives were recorded as the concentration of $\mathrm{HCl}$ and temperatures were higher. 
The Use Of Glutamic Acid As Corrosion Inhibitor For Aluminium In Hcl Solution

Table 1: Kinetic parameters for the corrosion inhibition of aluminium in HCl solution using glutamic acid as inhibitor

\begin{tabular}{|c|c|c|c|c|c|c|c|c|c|c|c|c|c|}
\hline \multirow{2}{*}{\multicolumn{2}{|c|}{$\begin{array}{l}\text { INHIBITOR CONC. } \\
\text { KINETIC PARAMETER }\end{array}$}} & \multicolumn{2}{|c|}{$0.0000 \mathrm{M}$} & \multicolumn{2}{|c|}{$0.0004 \mathrm{M}$} & \multicolumn{2}{|c|}{$0.0008 \mathrm{M}$} & \multicolumn{2}{|c|}{$0.0012 M$} & \multicolumn{2}{|c|}{$0.0016 \mathrm{M}$} & \multirow{2}{*}{$\frac{0.0020 \mathrm{M}}{\mathrm{k}_{1}}$} & \multirow[b]{2}{*}{$\mathbf{t}_{1 / 2}$} \\
\hline & & $\mathbf{k}_{1}$ & $\mathbf{t}_{1 / 2}$ & $\mathbf{k}_{1}$ & $\mathbf{t}_{1 / 2}$ & $\mathbf{k}_{1}$ & $\mathbf{t}_{1 / 2}$ & $\mathbf{k}_{1}$ & $\mathbf{t}_{1 / 2}$ & $\mathbf{k}_{1}$ & $\mathbf{t}_{1 / 2}$ & & \\
\hline \multirow{5}{*}{$323 K$} & $0.20 \mathrm{M} \mathrm{HCl}$ & 0.49 & 1.41 & 0.48 & 1.43 & 0.48 & 1.45 & 0.47 & 1.46 & 0.47 & 1.48 & 0.45 & 1.54 \\
\hline & $0.40 \mathrm{M} \mathrm{HCl}$ & 0.52 & 1.34 & 0.51 & 1.36 & 0.50 & 1.38 & 0.50 & 1.40 & 0.49 & 1.42 & 0.47 & 1.47 \\
\hline & $0.60 \mathrm{M} \mathrm{HCl}$ & 0.54 & 1.29 & 0.53 & 1.30 & 0.52 & 1.33 & 0.51 & 1.35 & 0.51 & 1.36 & 0.48 & 1.43 \\
\hline & $0.80 \mathrm{M} \mathrm{HCl}$ & 0.55 & 1.26 & 0.54 & 1.28 & 0.54 & 1.29 & 0.53 & 1.32 & 0.52 & 1.33 & 0.51 & 1.35 \\
\hline & $1.00 \mathrm{M} \mathrm{HCl}$ & 0.57 & 1.21 & 0.56 & 1.24 & 0.55 & 1.26 & 0.55 & 1.27 & 0.53 & 1.30 & 0.51 & 1.35 \\
\hline \multirow{5}{*}{$313 K$} & $0.20 \mathrm{M} \mathrm{HCl}$ & 0.63 & 1.10 & 0.62 & 1.12 & 0.61 & 1.13 & 0.60 & 1.15 & 0.59 & 1.17 & 0.57 & 1.22 \\
\hline & 0.40M HCl & 0.64 & 1.09 & 0.63 & 1.10 & 0.62 & 1.12 & 0.61 & 1.14 & 0.60 & 1.16 & 0.57 & 1.21 \\
\hline & $0.60 \mathrm{M} \mathrm{HCl}$ & 0.65 & 1.07 & 0.64 & 1.09 & 0.62 & 1.11 & 0.61 & 1.13 & 0.60 & 1.15 & 0.59 & 1.18 \\
\hline & $0.80 \mathrm{M} \mathrm{HCl}$ & 0.65 & 1.06 & 0.64 & 1.08 & 0.64 & 1.09 & 0.62 & 1.11 & 0.61 & 1.13 & 0.60 & 1.15 \\
\hline & $1.00 \mathrm{M} \mathrm{HCl}$ & 0.67 & 1.03 & 0.67 & 1.04 & 0.66 & 1.05 & 0.64 & 1.09 & 0.64 & 1.09 & 0.62 & 1.12 \\
\hline \multirow{5}{*}{ 303K } & $0.20 \mathrm{M} \mathrm{HCl}$ & 0.72 & 0.96 & 0.71 & 0.98 & 0.70 & 0.99 & 0.69 & 1.01 & 0.68 & 1.02 & 0.65 & 1.07 \\
\hline & $0.40 \mathrm{M} \mathrm{HCl}$ & 0.74 & 0.94 & 0.73 & 0.95 & 0.71 & 0.97 & 0.70 & 0.99 & 0.69 & 1.00 & 0.67 & 1.04 \\
\hline & $0.60 \mathrm{M} \mathrm{HCl}$ & 0.76 & 0.91 & 0.75 & 0.93 & 0.74 & 0.94 & 0.71 & 0.97 & 0.69 & 1.00 & 0.67 & 1.04 \\
\hline & $0.80 \mathrm{M} \mathrm{HCl}$ & 0.78 & 0.89 & 0.75 & 0.92 & 0.75 & 0.93 & 0.74 & 0.94 & 0.71 & 0.97 & 0.67 & 1.04 \\
\hline & $1.00 \mathrm{M} \mathrm{HCl}$ & 0.77 & 0.90 & 0.75 & 0.92 & 0.74 & 0.94 & 0.74 & 0.94 & 0.72 & 0.96 & 0.67 & 1.03 \\
\hline
\end{tabular}

\subsection{Corrosion rate and inhibition efficiencies}

To further establish the results of this study, values of corrosion rate and percentage inhibition efficiencies of aluminium in $\mathrm{HCl}$ solution with or without glutamic acid as inhibitor using weight loss, gasometric and thermometric methods was conducted. The results are as presented in TABLES 2 and 3 respectively. From the results obtained it is evident that the corrosion rates increases with increase in $\mathrm{HCl}$ concentration, increases with increase in temperature but decreases with increasing glutamic acid concentrations in all methods tested. The results also indicate that values of corrosion rate for weight loss is higher than those of gasometric and thermometric in all tested systems implying that the instantaneous corrosion rate of glutamic acid is better than the average corrosion rate [8]. This finding arises from the fact that gasometric and thermometric methods measure instantaneous corrosion rate while weight loss measure average corrosion rate. The inhibition efficiency (which is inversely proportional to corrosion rate) for the use of glutamic acid on aluminium surface in $\mathrm{HCl}$ was also calculated for all three methods (weight loss, gasometric and thermometric). From the results obtained it is evident that the inhibition efficiency decreases with increase in $\mathrm{HCl}$ concentration, decreases with increase in temperature but increases with increasing glutamic acid concentrations in all methods tested. These results signify that the inhibitor is an adsorption and that the adsorption of the inhibitor on aluminium surface favours the mechanism of physical adsorption $[16,17]$.

Table 2: Corrosion rates $\left(\mathrm{gh}^{-1} \mathrm{~cm}^{-2}\right)$ of aluminium in $\mathrm{HCl}$ solution containing various concentrations of glutamic acid at varying temperature

\begin{tabular}{|c|c|c|c|c|c|c|c|c|c|c|c|c|c|c|c|c|c|c|c|}
\hline \multirow{2}{*}{\multicolumn{2}{|c|}{$\begin{array}{l}\text { INC } \\
\text { CRC }\end{array}$}} & \multicolumn{3}{|c|}{$0.0000 \mathrm{M}$} & \multicolumn{3}{|c|}{$0.0004 M$} & \multicolumn{3}{|c|}{$0.0008 \mathrm{M}$} & \multicolumn{3}{|c|}{$0.0012 M$} & \multicolumn{3}{|c|}{$0.0016 \mathrm{M}$} & \multicolumn{3}{|c|}{$0.0020 \mathrm{M}$} \\
\hline & & WTL & & TMM & WTL & GSM : & TMM & WTL & GSM & TMM & WTL & GSM & MM & WTL & GSM & TMM & $\Gamma \mathrm{L}$ & GSM & TMN \\
\hline \multirow{5}{*}{ ల్ల } & $0.20 \mathrm{M}$ & 31 & 0.11 & 0.20 & 2.1 & 0.09 & 0.15 & 2.0 & 0.08 & 0.12 & 1.9 & 0.08 & 0.12 & 1.8 & 0.07 & 0.10 & 1.6 & 0.07 & 0.07 \\
\hline & $0.40 \mathrm{M}$ & 30 & 0.11 & 0.23 & 2.7 & 0.10 & 0.23 & 2.2 & 0.09 & 0.20 & 2.0 & 0.08 & 0.12 & 2.0 & 0.08 & 0.13 & 1.7 & 0.07 & 0.10 \\
\hline & $0.60 \mathrm{M}$ & 30 & 0.11 & 0.37 & 2.9 & 0.10 & 0.28 & 2.3 & 0.09 & 0.25 & 2.4 & 0.09 & 0.20 & 2.3 & 0.09 & 0.13 & 1.9 & 0.08 & 0.12 \\
\hline & $0.80 \mathrm{M}$ & 32 & 0.13 & 0.42 & 3.4 & 0.11 & 0.32 & 2.4 & 0.10 & 0.27 & 2.4 & 0.09 & 0.20 & 2.3 & 0.08 & 0.13 & 2.4 & 0.08 & 0.12 \\
\hline & $1.00 \mathrm{M}$ & 32 & 0.14 & 0.47 & 3.8 & 0.12 & 0.33 & 3.5 & 0.10 & 0.29 & 2.9 & 0.10 & 0.20 & 2.6 & 0.09 & 0.15 & 2.4 & 0.09 & 0.12 \\
\hline \multirow{5}{*}{$\frac{\mathscr{m}}{\mathrm{m}}$} & $0.20 \mathrm{M}$ & 35 & 0.85 & - & 3.2 & 0.78 & - & 2.7 & 0.75 & . & 2.4 & 0.73 & - & 2.8 & 0.70 & - & 2.5 & 0.66 & - \\
\hline & $0.40 \mathrm{M}$ & 36 & 0.89 & - & 3.6 & 0.79 & - & 2.9 & 0.76 & - & 2.6 & 0.74 & - & 3.0 & 0.70 & - & 2.8 & 0.68 & - \\
\hline & $0.60 \mathrm{M}$ & 37 & 0.90 & - & 4.2 & 0.82 & - & 2.9 & 0.78 & - & 2.6 & 0.75 & - & 3.1 & 0.72 & - & 2.9 & 0.68 & - \\
\hline & $0.80 \mathrm{M}$ & 37 & 0.92 & - & 4.4 & 0.85 & - & 3.8 & 0.78 & - & 2.7 & 0.76 & - & 3.2 & 0.71 & - & 3.1 & 0.68 & - \\
\hline & $1.00 \mathrm{M}$ & 39 & 0.94 & - & 4.6 & 0.87 & - & 4.1 & 0.84 & - & 2.8 & 0.82 & - & 3.6 & 0.80 & - & 3.5 & 0.75 & - \\
\hline \multirow{5}{*}{ लै } & $0.20 \mathrm{M}$ & 43 & 0.89 & - & 3.4 & 0.83 & - & 3.3 & 0.80 & - & 4.0 & 0.76 & - & 3.7 & 0.71 & - & 3.6 & 0.69 & - \\
\hline & $0.40 \mathrm{M}$ & 43 & 0.91 & - & 5.1 & 0.84 & - & 3.4 & 0.81 & - & 4.2 & 0.78 & - & 3.9 & 0.75 & - & 3.8 & 0.72 & - \\
\hline & $0.60 \mathrm{M}$ & 47 & 0.91 & - & 6.5 & 0.85 & - & 3.7 & 0.81 & - & 4.5 & 0.78 & - & 3.9 & 0.75 & - & 3.8 & 0.74 & - \\
\hline & $0.80 \mathrm{M}$ & 48 & 0.93 & - & 7.4 & 0.85 & - & 4.3 & 0.83 & - & 4.5 & 0.81 & - & 4.9 & 0.77 & - & 4.2 & 0.74 & - \\
\hline & $1.00 \mathrm{M}$ & 51 & 0.94 & - & 7.8 & 0.88 & - & 4.6 & 0.86 & - & 4.5 & 0.83 & - & 5.5 & 0.79 & - & 4.8 & 0.75 & - \\
\hline
\end{tabular}


The Use Of Glutamic Acid As Corrosion Inhibitor For Aluminium In Hcl Solution

Key: INC (Inhibitor Concentration), CRC (Corrodent Concentration), WTL (Weight Loss), GSM (Gasometric), TMM (Thermometric)

Table 3: Percentage Inhibition Efficiencies of aluminium in $\mathrm{HCl}$ solution containing various concentrations of glutamic acid at varying temperature

\begin{tabular}{|c|c|c|c|c|c|c|c|c|c|c|c|c|c|c|c|c|}
\hline & \multirow{2}{*}{$\begin{array}{l}\text { INC } \\
\text { CRC } \\
\end{array}$} & \multicolumn{3}{|c|}{$0.0004 \mathrm{M}$} & \multicolumn{3}{|c|}{$0.0008 \mathrm{M}$} & \multicolumn{3}{|c|}{$0.0012 M$} & \multicolumn{3}{|c|}{$0.0016 M$} & \multicolumn{3}{|c|}{$0.0020 \mathrm{M}$} \\
\hline & & WTL & GSM & TMM & WTL & GSM & TMM & WTL & GSM & TMM & WTL & GSM & TMM & WTL & GSM & TMM \\
\hline \multirow{5}{*}{ ֻै } & $0.20 \mathrm{M}$ & 12.16 & 14.62 & 25.00 & 16.86 & 22.31 & 41.67 & 18.30 & 30.00 & 51.67 & 20.05 & 31.54 & 52.00 & 20.54 & 33.85 & 66.67 \\
\hline & $0.40 \mathrm{M}$ & 10.63 & 16.18 & 24.00 & 16.28 & 21.32 & 34.29 & 18.10 & 28.68 & 50.00 & 20.01 & 33.09 & 42.86 & 22.09 & 36.03 & 65.14 \\
\hline & $0.60 \mathrm{M}$ & 9.78 & 13.33 & 22.73 & 12.53 & 16.30 & 36.82 & 15.27 & 20.00 & 45.45 & 18.02 & 23.70 & 49.09 & 20.05 & 26.67 & 58.18 \\
\hline & $0.80 \mathrm{M}$ & 9.60 & 14.00 & 23.00 & 12.55 & 24.00 & 31.00 & 14.64 & 27.33 & 42.00 & 16.96 & 34.00 & 48.00 & 18.54 & 35.33 & 56.00 \\
\hline & $1.00 \mathrm{M}$ & 8.77 & 17.06 & 22.71 & 13.80 & 28.24 & 30.43 & 13.90 & 30.00 & 41.14 & 16.46 & 33.53 & 47.86 & 17.88 & 39.41 & 55.00 \\
\hline \multirow{5}{*}{$\frac{\text { लै }}{\frac{\pi}{n}}$} & $0.20 \mathrm{M}$ & 4.75 & 7.19 & - & 7.74 & 11.71 & - & 9.32 & 14.93 & - & 11.06 & 22.85 & - & 13.14 & 26.68 & - \\
\hline & $0.40 \mathrm{M}$ & 4.63 & 7.10 & - & 7.57 & 14.46 & - & 8.81 & 16.90 & - & 11.06 & 21.13 & - & 12.78 & 25.92 & - \\
\hline & $0.60 \mathrm{M}$ & 3.98 & 6.94 & - & 6.67 & 14.01 & - & 7.50 & 17.05 & - & 10.10 & 20.55 & - & 12.78 & 24.98 & - \\
\hline & $0.80 \mathrm{M}$ & 3.97 & 6.00 & - & 5.95 & 14.53 & - & 7.49 & 17.44 & - & 9.86 & 22.43 & - & 11.86 & 28.25 & - \\
\hline & $1.00 \mathrm{M}$ & 3.46 & 5.78 & - & 5.05 & 10.22 & - & 6.76 & 12.44 & - & 9.68 & 14.76 & - & 11.18 & 19.64 & - \\
\hline \multirow{5}{*}{ लै } & $0.20 \mathrm{M}$ & 3.48 & 4.29 & - & 4.93 & 10.50 & - & 6.73 & 14.90 & - & 9.02 & 19.87 & - & 10.78 & 22.77 & - \\
\hline & $0.40 \mathrm{M}$ & 3.27 & 11.08 & - & 4.26 & 10.48 & - & 6.21 & 13.51 & - & 8.84 & 17.83 & - & 10.66 & 20.77 & - \\
\hline & $0.60 \mathrm{M}$ & 3.24 & 9.59 & - & 4.22 & 10.17 & - & 5.97 & 12.61 & - & 8.49 & 17.44 & - & 10.53 & 22.30 & - \\
\hline & $0.80 \mathrm{M}$ & 2.97 & 7.54 & - & 3.90 & 10.06 & - & 5.42 & 12.31 & - & 7.98 & 16.71 & - & 10.40 & 20.22 & - \\
\hline & $1.00 \mathrm{M}$ & 2.63 & 6.84 & - & 3.50 & 8.27 & - & 5.25 & 11.03 & - & 7.35 & 15.66 & - & 9.94 & 19.57 & - \\
\hline
\end{tabular}

Key: INC (Inhibitor Concentration), CRC (Corrodent Concentration), WTL (Weight Loss), GSM (Gasometric), TMM (Thermometric)

\subsection{Thermodynamic considerations}

\subsubsection{Effect of temperature}

In order to study the effect of temperature on the corrosion of aluminium in varying concentrations of $\mathrm{HCl}$ containing various concentrations of glutamic acid, the Arrhenius equation (10) was used:

$$
C R=A \exp ^{\left(\frac{-E a}{R T}\right)}
$$

Taking logarithm of both sides at a particular temperature gives equation (11), while at two different temperatures gives equation (12):

$$
\begin{aligned}
& \log (C R)=\log A-\frac{E_{a}}{2.303} R T \\
& \log \left(\frac{C R_{2}}{C R_{1}}\right)=\frac{E_{a}}{2.303 R}\left(\frac{1}{T_{1}}-\frac{1}{T_{2}}\right)
\end{aligned}
$$

Where $\mathrm{CR}_{1}$ and $\mathrm{CR}_{2}$ are the corrosion rates of aluminium at temperatures $\mathrm{T}_{1}(303 \mathrm{~K})$ and $\mathrm{T}_{2}(323 \mathrm{~K})$ respectively, $E_{a}$ is the activation energy and $R$ is the $g$ constant. Calculated values of activation energy using equation (12) are presented in TABLE 4. Effect of corrodent concentration and inhibitor concentrations were taken into consideration. It was observed that the values obtained in the presence of the inhibitor were all greater than those without inhibitor at all systems tested, indicating that the inhibitor increases the activation energy and thereby decreasing the rate of reaction. It was also observed that, as the concentration of the inhibitor increases there is an increase in activation energy, also as the concentration of $\mathrm{HCl}$ increases the activation energy decreases thereby increasing the rate of corrosion. It can also be observed from TABLE 4 that the activation energies are less than the threshold value of $80 \mathrm{KJ} / \mathrm{mol}$ which is required for the mechanism of chemical adsorption. Therefore the adsorption of glutamic acid on the surface of aluminium is consistent with the mechanism of physical adsorption [19].

The heat of adsorption $\mathrm{Q}_{\mathrm{ads}}$ of glutamic acid on the surface of aluminium in $\mathrm{HCl}$ solution was calculated using equation (13):

$$
Q_{a d s}=2.303 R\left[\log \left(\frac{\vartheta_{2}}{1-\vartheta_{2}}\right)-\log \left(\frac{\vartheta_{1}}{1-\vartheta_{1}}\right)\right] \times \frac{T_{1} \times T_{2}}{T_{2}-T_{1}} \frac{K J}{m o l s}
$$

Where $\mathrm{Q}_{\text {ads }}$ is the heat of adsorption of the glutamic acid on the surface of aluminium, $\mathrm{R}$ is the gas constant, $\theta_{1}$ and $\theta_{2}$ are the degrees of surface coverage of glutamic acid at $303 \mathrm{~K}\left(\mathrm{~T}_{1}\right)$ and $323 \mathrm{~K}\left(\mathrm{~T}_{2}\right)$ respectively. Calculated values of $\mathrm{Q}_{\mathrm{ads}}$ are also presented in TABLE 4 . These values were all negative and tend to decrease with $\mathrm{HCl}$ concentration and increase with glutamic acid concentration indicating that the adsorption of glutamic acid on the surface of aluminium in $\mathrm{HCl}$ is in all cases tested exothermic. 
The Use Of Glutamic Acid As Corrosion Inhibitor For Aluminium In Hcl Solution

Table 4: Some adsorption parameters for the inhibition of the corrosion of aluminium in varying $\mathrm{HCl}$ solution by glutamic acid

\begin{tabular}{|c|c|c|c|c|c|c|c|c|c|c|c|c|}
\hline \multirow{2}{*}{$\begin{array}{l}\text { Inhibitor } \\
\text { Conc. } \\
\text { Corrodent } \\
\text { Conc. } \\
\end{array}$} & \multicolumn{2}{|c|}{$0.0000 \mathrm{M}$} & \multicolumn{2}{|c|}{$0.0004 \mathrm{M}$} & \multicolumn{2}{|c|}{$0.0008 \mathrm{M}$} & \multicolumn{2}{|c|}{$0.0012 M$} & \multicolumn{2}{|c|}{$0.0016 M$} & \multicolumn{2}{|c|}{$0.0020 \mathrm{M}$} \\
\hline & $\mathbf{E}_{\mathbf{a}}$ & $\mathbf{Q}_{\text {ads }}$ & $\mathbf{E}_{\mathbf{a}}$ & $\mathbf{Q}_{\text {ads }}$ & $\mathbf{E}_{\mathbf{a}}$ & $\mathbf{Q}_{\text {ads }}$ & $\mathbf{E}_{\mathbf{a}}$ & $\mathbf{Q}_{\text {ads }}$ & $\mathbf{E}_{\mathbf{a}}$ & $\mathbf{Q}_{\text {ads }}$ & $\mathbf{E}_{\mathrm{a}}$ & $\mathbf{Q}_{\text {ads }}$ \\
\hline $0.20 \mathrm{M}$ & -55.30 & 0.00 & -54.98 & -41.58 & -47.02 & -46.57 & -28.68 & -48.10 & -26.64 & -48.27 & -24.86 & -49.79 \\
\hline $0.40 \mathrm{M}$ & -52.51 & 0.00 & -52.48 & -36.87 & -37.14 & -36.98 & -25.28 & -42.05 & -22.57 & -42.78 & -20.63 & -49.11 \\
\hline $0.60 \mathrm{M}$ & -42.13 & 0.00 & -32.66 & -36.47 & -27.25 & -39.61 & -23.66 & -36.61 & -20.51 & -40.93 & -19.59 & -41.83 \\
\hline $0.80 \mathrm{M}$ & -22.08 & 0.00 & -14.86 & -34.56 & -16.99 & -36.60 & -15.12 & -36.03 & -13.34 & -33.57 & -11.12 & -31.41 \\
\hline $1.00 \mathrm{M}$ & -16.78 & 0.00 & -12.49 & -34.08 & -8.52 & -34.36 & -5.45 & -33.54 & -11.23 & -33.22 & -10.18 & -30.69 \\
\hline
\end{tabular}

\subsubsection{Entropy and enthalpy of adsorption}

In order to calculate some other thermodynamic parameters for the adsorption $\left(\Delta \mathrm{S}_{\mathrm{ads}}\right.$ and $\left.\Delta \mathrm{H}_{\mathrm{ads}}\right)$ of glutamic acid on aluminium surface, the transition state equation (13) was used:

$\log \left(\frac{C R}{T}\right)=\log \left(\frac{R}{N h}\right)+\frac{\Delta S_{a d s}}{2.303 R}-\frac{\Delta H_{a d s}}{2.303 R T}$

Where CR is the corrosion rate, $\mathrm{T}$ is absolute temperature, $\mathrm{R}$ is gas constant, $\mathrm{N}$ is Avogadros constant, $\mathrm{h}$ is planks constant, $\Delta \mathrm{S}_{\mathrm{ads}}$ and $\Delta \mathrm{H}_{\mathrm{ads}}$ are entropy and enthalpy of adsorption. From this equation (13), a plot of $\log (\mathrm{CR} / \mathrm{T})$ versus $1 / \mathrm{T}$ gave a straight line with a slope and intercept equal to $-\Delta \mathrm{H}_{\mathrm{ads}} / 2.303 \mathrm{R}$ and $[\log (\mathrm{R} / \mathrm{Nh})+$ $\left.\Delta \mathrm{S}_{\mathrm{ads}} / 2.303 \mathrm{R}\right]$. Values of $\Delta \mathrm{S}_{\mathrm{ads}}$ and $\Delta \mathrm{H}_{\mathrm{ads}}$ calculated from equation (13) are recorded in Table 5. The negative values of $\Delta \mathrm{H}_{\mathrm{ads}}$ indicated that the corrosion of aluminium inhibited by glutamic acid is exothermic and decrease with increase in glutamic acid concentration but increases with $\mathrm{HCl}$ concentration increase, both suggesting a feasible reaction. It was also observed that $\mathrm{Q}_{\mathrm{ads}}, \mathrm{E}_{\mathrm{a}}$ and $\Delta \mathrm{H}_{\mathrm{ads}}$ strongly correlated $\left(\mathrm{R}^{2}\right.$ value of 0.9988$)$. This can be explained with the fact that the enthalpy change of a reaction can be represented as in equation (14):

$\Delta \mathrm{H}_{\mathrm{ads}}=\mathrm{E}_{\mathrm{a}}+\mathrm{PdV}$

For reactions involving liquids, $\mathrm{dV}$ is negligible implying that values of $\Delta \mathrm{H}_{\text {ads }}$ should be equivalent to those of $E_{a}[6]$.

Table 5: Enthalpy and entropy of adsorption of glutamic acid on the surface of aluminium in $\mathrm{HCl}$ solution

\begin{tabular}{|c|c|c|c|c|c|c|c|c|c|c|c|c|}
\hline \multirow{2}{*}{$\begin{array}{l}\text { INHIB CONC } \\
\text { CORR CONC }\end{array}$} & \multicolumn{2}{|c|}{$0.0000 M$} & \multicolumn{2}{|c|}{$0.0004 M$} & \multicolumn{2}{|c|}{$0.0008 \mathrm{M}$} & \multicolumn{2}{|c|}{$0.0012 M$} & \multicolumn{2}{|c|}{$0.0016 M$} & \multicolumn{2}{|c|}{$0.0020 \mathrm{M}$} \\
\hline & $\Delta \mathbf{H}$ & $\Delta \mathbf{S}$ & $\Delta \mathbf{H}$ & $\Delta \mathbf{S}$ & $\Delta \mathbf{H}$ & $\Delta \mathbf{S}$ & $\Delta \mathbf{H}$ & $\Delta \mathbf{S}$ & $\Delta \mathbf{H}$ & $\Delta \mathbf{S}$ & $\Delta \mathbf{H}$ & $\Delta \mathbf{S}$ \\
\hline $0.20 \mathrm{M}$ & -10.68 & 0.28 & -46.35 & 0.29 & -44.21 & 0.30 & -42.90 & 0.33 & -28.69 & 0.33 & -28.00 & 0.34 \\
\hline $0.40 \mathrm{M}$ & -11.91 & 0.27 & -59.82 & 0.27 & -48.32 & 0.28 & -41.31 & 0.30 & -25.34 & 0.31 & -24.51 & 0.32 \\
\hline $0.60 \mathrm{M}$ & -12.52 & 0.26 & -57.56 & 0.26 & -42.76 & 0.27 & -31.45 & 0.28 & -25.20 & 0.30 & -23.65 & 0.31 \\
\hline $0.80 \mathrm{M}$ & -14.44 & 0.26 & -47.39 & 0.24 & -32.73 & 0.25 & -28.06 & 0.26 & -25.16 & 0.28 & -22.86 & 0.29 \\
\hline $1.00 \mathrm{M}$ & -16.12 & 0.26 & -42.20 & 0.24 & -31.75 & 0.25 & -26.27 & 0.25 & -24.44 & 0.25 & -22.58 & 0.25 \\
\hline
\end{tabular}

3.6.3 Free energy of Adsorption

The Gibb's free energy of adsorption of glutamic acid onto the surface of aluminium in $\mathrm{HCl}$ solution was calculated at three different temperatures using the Gibbs-Helmholtz equation (15):

$\Delta \mathrm{G}_{\mathrm{ads}}=\Delta \mathrm{H}_{\mathrm{ads}}-\mathrm{T} \Delta \mathrm{S}_{\mathrm{ads}}$

where $\Delta \mathrm{G}_{\mathrm{ads}}$ is the free energy of glutamic acid adsorption onto aluminium surface, $\Delta \mathrm{H}_{\mathrm{ads}}$ is the enthalpy of its adsorption and $\Delta \mathrm{S}_{\mathrm{ads}}$ is the entropy of adsorption and $\mathrm{T}$ is the temperature $(\mathrm{K})$. The calculated values of the free energy are as presented in table (6). From the results obtained the free energies were found to increase with temperature, decrease with inhibitor concentration and increase with corrodent concentration. However all these values are lower in actual value than the threshold of $-40 \mathrm{KJ} / \mathrm{mol}$ required for chemical adsorption. This indicates that the adsorption of glutamic acid onto the surface of aluminium is spontaneous and also supports the mechanism of physical adsorption [8]. 
The Use Of Glutamic Acid As Corrosion Inhibitor For Aluminium In Hcl Solution

Table 6: Gibb's free energy of adsorption of glutamic acid onto aluminium surface in HCl solution at varying temperatures

\begin{tabular}{|c|c|c|c|c|}
\hline \multirow[b]{2}{*}{ CORRODENT CONC } & \multirow[b]{2}{*}{ INHIBITOR CONC } & \multicolumn{3}{|c|}{ TEMPERATURE } \\
\hline & & 303K & 313K & 323K \\
\hline \multirow{6}{*}{$0.20 \mathrm{M}$} & $0.0000 M$ & -94.67 & -97.44 & -100.21 \\
\hline & $0.0004 \mathrm{M}$ & -102.93 & -104.80 & -106.66 \\
\hline & $0.0008 M$ & -102.02 & -103.60 & -105.78 \\
\hline & $0.0012 M$ & -101.10 & -103.41 & -105.73 \\
\hline & $0.0016 M$ & -100.64 & -103.01 & -105.39 \\
\hline & $0.0020 M$ & -100.13 & -102.58 & -105.03 \\
\hline \multirow{6}{*}{$0.40 \mathrm{M}$} & $0.0000 \mathrm{M}$ & -94.69 & -97.42 & -100.16 \\
\hline & $0.0004 M$ & -103.96 & -105.42 & -106.88 \\
\hline & $0.0008 M$ & -102.60 & -104.39 & -106.18 \\
\hline & $0.0012 M$ & -101.20 & -103.51 & -105.81 \\
\hline & $0.0016 M$ & -100.58 & -103.06 & -105.54 \\
\hline & $0.0020 \mathrm{M}$ & -100.16 & -102.69 & -105.22 \\
\hline \multirow{6}{*}{$0.60 \mathrm{M}$} & $0.0000 \mathrm{M}$ & -94.72 & -97.34 & -99.95 \\
\hline & $0.0004 M$ & -102.84 & -104.00 & -105.17 \\
\hline & $0.0008 M$ & -101.67 & -103.29 & -104.90 \\
\hline & $0.0012 M$ & -100.94 & -102.77 & -104.60 \\
\hline & $0.0016 M$ & -100.42 & -102.38 & -104.34 \\
\hline & $0.0020 \mathrm{M}$ & -99.91 & -102.04 & -104.16 \\
\hline \multirow{6}{*}{$0.80 \mathrm{M}$} & $0.0000 \mathrm{M}$ & -94.61 & -97.26 & -99.90 \\
\hline & $0.0004 M$ & -102.98 & -104.81 & -106.65 \\
\hline & $0.0008 M$ & -101.70 & -103.97 & -106.25 \\
\hline & $0.0012 M$ & -101.03 & -103.44 & -105.84 \\
\hline & $0.0016 \mathrm{M}$ & -100.47 & -102.96 & -105.44 \\
\hline & $0.0020 \mathrm{M}$ & -100.04 & -102.61 & -105.18 \\
\hline \multirow{6}{*}{$1.00 \mathrm{M}$} & $0.0000 M$ & -94.56 & -97.15 & -99.74 \\
\hline & $0.0004 M$ & -102.40 & -104.39 & -106.37 \\
\hline & $0.0008 M$ & -101.38 & -103.67 & -105.97 \\
\hline & $0.0012 M$ & -100.67 & -103.13 & -105.58 \\
\hline & $0.0016 M$ & -100.25 & -102.75 & -105.26 \\
\hline & $0.0020 M$ & -99.83 & -102.38 & -104.93 \\
\hline
\end{tabular}

\subsubsection{Adsorption isotherm models}

Generally, four types of adsorptions may take place, involving organic molecules at the metal solution interface, namely; the electrolytic attraction between charged molecules and the charged metal, interaction of unshared electron pairs in the molecules with the metal, interaction of s electrons with metal and combination of the above [6]. These mechanisms are usually described by adsorption isotherms. The adsorption behaviour of glutamic acid was studied by fitting data obtained from degree of surface coverage to different adsorption isotherms including Langmuir, Temkin, Frumkin, Flory-Huggins and El-Awardy adsorption isotherms. The tests reveal that the adsorption of glutamic acid on aluminium surface is best described by Langmuir, ElAwardy, Frumkin and Flory-huggins adsorption isotherms in decreasing order based on plot correlation coefficient $\left(\mathrm{R}^{2}\right)$ values.

The adsorption behaviour of glutamic acid was studied by fitting the data obtained on the expression of Langmuir adsorption isotherm model as in equation (15):

$\frac{C}{\vartheta}=\frac{1}{K_{a d s}}+C$

Taking logarithm of both sides yielded equation (16)

$\log \left(\frac{\mathrm{C}}{9}\right)=\log C-\log K_{a d s}$

where $\mathrm{C}$ is the concentration of the inhibitor in the sollution, $\theta$ is the degree of surface coverage of the inhibitor, and $K_{\text {ads }}$ is the equilibrium constant of adsorption. Using equation (16), a plot of $\log (\mathrm{C} / \theta)$ versus $\log C$ was found to be linear, indicating the application of the Langmuir model to the adsorption of glutamic acid on aluminium surface. Values of Langmuir adsorption parameters deduced from the slopes and intercept of the plots are presented in Table 7. From the results obtained, the slopes and values of $\mathrm{R}^{2}$ are very close to unity indicating that there is a strong adherence of the inhibitor adsorption to the assumption of Langmuir isotherm; mono layer adsorption and non interaction of adsorbed molecules [8]. 
According to Temkin adsorption isotherm, the degree of surface coverage $(\theta)$ is related to the concentration of the inhibitor $(C)$ in the bulk electrolyte according to equation (17):

$\exp (-2 a \vartheta)=K C$

Upon taking the logarithm of both sides and re-arranging, equation (18) and (19) resulted:

$\vartheta=\frac{-2.303 \log K}{2 a}-\frac{2.303 \log C}{2 a}$

$\vartheta=\frac{-\ln K}{2 a}-\frac{\ln C}{2 a}$

Where $\mathrm{K}$ and a are the equilibrium constant of adsorption and Temkin interaction parameter. The plots of $\theta$ versus $\log C$ were not linear and have a very low $\mathrm{R}^{2}$ values indicating that the adsorption of the inhibitor was not consistent with the assumptions of temkin all conditions tested. Values of the adsorption parameters deduced from Temkin plots are recorded in Table 7.

The adsorption of glutamic acid on aluminium surface was also tested using Frumkin adsorption isotherm which can be expressed as in equation (20)

$\log \left(C \times \frac{\vartheta}{1-\vartheta}\right)=2.303 \log K+2 \alpha \vartheta$

Where $\mathrm{K}$ is the adsorption-desorption equilibrium constant and $\alpha$ is the lateral interaction term describing the molecular interaction in the adsorbed layer. A plot of $\log (\mathrm{C} \times \theta / 1-\theta)$ versus $\theta$ was made, where $\mathrm{K}$ and $\alpha$ values where obtained from the slope and intercept respectively. Values of Frumkin adsorption isotherm are also presented in Table 7. From the results, values of $\alpha$ where found to be positive which also indicate the attractive behaviour of the inhibitor on the surface of aluminium which was found to decrease with increase in $\mathrm{HCl}$ concentration and increase with inhibitor concentration [19].

The values of $\theta / C$ in the plots (not shown) were evaluated directly from equation (21) determined from the weight loss data. It was found that the experimental data obtained within the temperature range $(303,313$ and $323 \mathrm{~K}$ ) fits Flory-Huggins adsorption isotherm which is given by equation (21):

$\log \left(\frac{\vartheta}{C}\right)=\log K+x \log (1-\vartheta)$

where $\theta$ is the degree of surface coverage, $x$ the number of inhibitor molecules occupying an active site (or the number of water molecules replaced by one molecule of glutamic acid), $K$ the equilibrium constant of adsorption and $C$ is the different concentrations of the systems studied. The plot of $\log (\theta / C)$ versus $\log (1-\theta)$ for Flory-Huggins' isotherm at $303 \mathrm{~K}$ gave straight lines for aluminium in all concentrations of $\mathrm{HCl}$ in the presence of glutamic acid (inhibitor). Similar trend was observed at 313 and $323 \mathrm{~K}$ respectively. Results from Table 7 shows that values of $\mathrm{x}$ decreases with increase in $\mathrm{HCl}$ concentration and also temperature. This clearly indicates that the rate of glutamic acid adsorption on the surface of the aluminium metal decreases with increase in temperature and $\mathrm{HCl}$ concentrations [10].

The plot of $\log (\theta / 1-\theta)$ against $\log C$ was made and straight lines were obtained which showed that the results obtained from the study also fitted into the El-Awady et al. thermodynamic-kinetic model which is given by equation (22):

$\log \left(\frac{\vartheta}{1-\vartheta}\right)=\log K+y \log C$

Where $\theta$ is the degree of surface coverage of the inhibitor, $K$ is the equilibrium constant of adsorption, $1 / y$ represents the active sites on metal surface covered by inhibitor molecules [10]. The values of $y$ is increasing or $1 / \mathrm{y}$ dcreasing as temperature and $\mathrm{HCl}$ concentration decreases. This also reveals that the number of active sites replaced by the inhibitor molecules decreases with increase in temperature and $\mathrm{HCl}$ concentrations. From the results obtained it is seen that $\mathrm{K}$ values increase with increase in temperature. Generally larger $\mathrm{K}$ values imply more efficient adsorption and hence a better inhibitor. Therefore the adsorption of glutamic acid on the surface of aluminium is retarded by increase in temperature supporting the mechanism of physical adsorption [19].

Table 7: Adsorption isotherm model parameters for the adsorption of glutamic acid on aluminium surface in $\mathrm{HCl}$ solution at varying temperatures

\begin{tabular}{|c|c|c|c|c|c|c|c|c|c|c|}
\hline \multirow{2}{*}{\multicolumn{2}{|c|}{$\begin{array}{c}\text { Corrodent } \\
(\mathrm{HCl})\end{array}$}} & \multicolumn{3}{|c|}{$303 K$} & \multicolumn{3}{|c|}{ 313K } & \multicolumn{3}{|c|}{ 323K } \\
\hline & & $\mathbf{R}^{2}$ & Slope & $\mathbf{K}$ & $\mathbf{R}^{2}$ & Slope & $\mathbf{K}$ & $\mathbf{R}^{2}$ & Slope & $\mathbf{K}$ \\
\hline \multirow{5}{*}{ 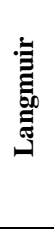 } & $0.20 \mathrm{M}$ & 0.91 & 0.75 & 0.73 & 0.97 & 0.36 & 0.20 & 0.99 & 0.39 & 1.07 \\
\hline & $0.40 \mathrm{M}$ & 1.00 & 0.71 & 0.75 & 0.97 & 0.10 & 0.30 & 0.94 & 0.18 & 1.08 \\
\hline & $0.60 \mathrm{M}$ & 0.99 & 0.55 & 0.81 & 0.99 & 0.28 & 0.41 & 1.00 & 0.76 & 1.09 \\
\hline & $0.80 \mathrm{M}$ & 0.99 & 0.67 & 0.90 & 1.00 & 0.29 & 0.43 & 1.00 & 0.63 & 1.09 \\
\hline & $1.00 \mathrm{M}$ & 0.99 & 0.68 & 0.93 & 1.00 & 0.38 & 0.52 & 1.00 & 0.64 & 1.17 \\
\hline \multirow{3}{*}{ 兽 } & & $\mathbf{R}^{2}$ & $\mathbf{a}$ & $\mathbf{K}$ & $\mathbf{R}^{2}$ & $\mathbf{A}$ & $\mathbf{K}$ & $\mathbf{R}^{2}$ & $\mathbf{a}$ & $\mathbf{K}$ \\
\hline & $0.20 \mathrm{M}$ & 0.47 & 12.97 & 0.90 & 0.40 & -64.69 & 0.25 & 0.44 & -45.88 & 0.27 \\
\hline & $0.40 \mathrm{M}$ & 0.77 & 9.84 & 0.33 & 0.28 & -66.56 & 0.16 & 0.32 & -69.79 & 0.19 \\
\hline
\end{tabular}


The Use Of Glutamic Acid As Corrosion Inhibitor For Aluminium In Hcl Solution

\begin{tabular}{|c|c|c|c|c|c|c|c|c|c|c|}
\hline & $0.60 M$ & 0.55 & -26.84 & 0.35 & 0.36 & -63.27 & 0.22 & 0.75 & -22.02 & 0.51 \\
\hline & $0.80 \mathrm{M}$ & 0.05 & -26.72 & 0.43 & 0.37 & -68.54 & 0.22 & 0.48 & -48.79 & 0.30 \\
\hline & $1.00 \mathrm{M}$ & 0.67 & -24.82 & 0.45 & 0.43 & -60.93 & 0.27 & 0.50 & -46.62 & 0.32 \\
\hline \multirow{6}{*}{ 咅 } & & $\mathbf{R}^{2}$ & $\alpha$ & $\mathbf{K}$ & $\mathbf{R}^{2}$ & $\mathrm{~A}$ & $\mathbf{K}$ & $\mathbf{R}^{2}$ & $\alpha$ & $\mathbf{K}$ \\
\hline & $0.20 \mathrm{M}$ & 0.68 & 4.22 & 0.01 & 0.96 & 9.16 & 0.00 & 0.98 & 7.12 & 0.00 \\
\hline & $0.40 \mathrm{M}$ & 0.98 & 5.64 & 0.00 & 0.96 & 8.94 & 0.01 & 0.97 & 8.99 & 0.00 \\
\hline & $0.60 \mathrm{M}$ & 0.98 & 5.05 & 0.01 & 0.96 & 8.47 & 0.00 & 0.97 & 8.53 & 0.00 \\
\hline & $0.80 \mathrm{M}$ & 0.96 & 5.04 & 0.00 & 0.97 & 8.46 & 0.00 & 0.97 & 7.95 & 0.00 \\
\hline & $1.00 \mathrm{M}$ & 0.96 & 4.91 & 0.00 & 0.98 & 8.22 & 0.00 & 0.96 & 7.77 & 0.00 \\
\hline \multirow{6}{*}{ 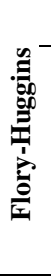 } & & $\mathbf{R}^{2}$ & $\mathbf{x}$ & $\mathbf{K}$ & $\mathbf{R}^{2}$ & $\mathbf{X}$ & $\mathbf{K}$ & $\mathbf{R}^{2}$ & $\mathbf{x}$ & $\mathbf{K}$ \\
\hline & $0.20 \mathrm{M}$ & 0.17 & 10.81 & 418.12 & 0.83 & 8.01 & 102.73 & 0.95 & 6.84 & 162.07 \\
\hline & $0.40 \mathrm{M}$ & 0.94 & 10.30 & 1509.38 & 0.29 & 7.43 & 64.24 & 0.91 & 5.72 & 70.96 \\
\hline & $0.60 \mathrm{M}$ & 0.92 & 9.93 & 440.86 & 0.88 & 6.53 & 90.89 & 0.92 & 5.16 & 2496.32 \\
\hline & $0.80 \mathrm{M}$ & 0.87 & 9.86 & 785.60 & 0.96 & 6.15 & 87.30 & 0.91 & 4.59 & 183.82 \\
\hline & $1.00 \mathrm{M}$ & 0.89 & 9.01 & 989.46 & 0.95 & 5.97 & 120.01 & 0.86 & 4.02 & 206.25 \\
\hline \multirow{6}{*}{$\begin{array}{l}\stackrel{Z}{*} \\
\frac{1}{3} \\
\frac{1}{1}\end{array}$} & & $\mathbf{R}^{2}$ & $\mathbf{y}$ & $\mathbf{K}$ & $\mathbf{R}^{2}$ & $\mathbf{Y}$ & $\mathbf{K}$ & $\mathbf{R}^{2}$ & $\mathbf{y}$ & $\mathbf{K}$ \\
\hline & $0.20 \mathrm{M}$ & 0.51 & 0.30 & 1.61 & 0.99 & 0.68 & 7.01 & 0.99 & 0.47 & 9.46 \\
\hline & $0.40 \mathrm{M}$ & 0.99 & 0.36 & 2.48 & 0.98 & 0.69 & 45.07 & 1.00 & 0.57 & 23.83 \\
\hline & $0.60 \mathrm{M}$ & 0.99 & 0.52 & 6.34 & 1.00 & 0.75 & 13.30 & 0.97 & 0.69 & 1.57 \\
\hline & $0.80 \mathrm{M}$ & 0.96 & 0.59 & 2.47 & 1.00 & 0.77 & 11.13 & 0.99 & 0.72 & 4.79 \\
\hline & $1.00 \mathrm{M}$ & 0.97 & 0.67 & 2.39 & 1.00 & 0.86 & 6.56 & 0.98 & 0.85 & 3.96 \\
\hline
\end{tabular}

\section{Conclusion}

The adsorptive and inhibitive properties of Glutamic acid was studied on aluminium surface corrosion in $\mathrm{HCl}$ solution at varying temperature, inhibitor and corrodent concentrations using weight loss, gasometric and thermometric methods. From the findings of this work, the following conclusions can be drawn;

1. Glutamic acid was found to inhibit aluminium corrosion in $\mathrm{HCl}$ solution.

2. Increase in the concentration of glutamic acid decreases the rate of aluminium corrosion in $\mathrm{HCl}$ and therefore increases the inhibition efficiency.

3. Higher concentration and temperatures reduced the inhibitive effect of glutamic acid on the corrosion of aluminium in $\mathrm{HCl}$ solution.

4. The corrosion reaction in the presence and absence of glutamic acid was found to follow first order kinetics and its half lives increases with glutamic acid concentration, but decreases with increase in temperature and $\mathrm{HCl}$ concentration.

5. The thermodynamic parameters ( $\mathrm{Ea}, \mathrm{Q}_{\mathrm{ads}}, \Delta \mathrm{S}_{\mathrm{ads}}, \Delta \mathrm{H}_{\mathrm{ads}}, \Delta \mathrm{G}_{\mathrm{ads}}$ ) for the adsorption of glutamic acid to the surface of aluminium in $\mathrm{HCl}$ was found to obey the mechanism of physical adsorption.

6. The adsorption of glutamic acid onto the surface of aluminium in $\mathrm{HCl}$ solution was found to follow the models of Langmuir, Frumkin, Flory-Huggins and kinetic and thermodynamic El-Awardy adsorption isotherms.

\section{References}

[1] E. E. Oguzie; B. N. Okolue,; E. E. Ebenso; G. N. Onuoha; A. I. Onuchukwu, Evaluation of the Inhibitory Effect of Methylene Blue Dye on the Corrosion of Aluminium in Hydrochloric Acid, Materials Chemistry and Physics 87, 2004, 394-401.

[2] K. F. Khaled; M. M. Al-Qahtani, The inhibitive Effect of Some Tetrazole Derivatives Towards Al Corrosion in Acid Solution: Chemical, Electrochemical and Theoretical Studies, Materials Chemistry and Physics, 113, 2009, 150-158.

[3] L. Kobotiatis; N. Pebere; P. G. Koutsoukos, Study of the Electrochemical Behaviour of the 7075 Aluminium Alloy in the Presence of Sodium Oxalate, Corrosion Science, 41, 1999, 941-957.

[4] Y. Xiao-Ci; Z. Hong; L. Ming-Dao; R. Hong-Xuan; Y. Lu-An, Quantum Chemical Study of the Inhibition Properties of Pyridine and its Derivatives at an Aluminium Surface, Corrosion Science, 42, 2000, 645-653.

[5] G. Bereket and A. Yurt, The Inhibition Effect of Amnio Acids and Hydroxycarboxylic Acids on Pitting Corrosion of Aluminium Alloy 7075, Corrosion Science, 43, 2001, 1179-1195.

[6] N. O. Eddy; P. A. Ekwumemgbo; P. A. P. Mamza, Ethanol Extract of Terminalia Catappa as a Green Inhibitor for the Corrosion of Mild Steel in $\mathrm{H}_{2} \mathrm{SO}_{4}$, Green Chemistry Letters and Reviews, 2(4), 2009, 223-231.

[7] E. E. Ebenso; N. O. Eddy; A. O. Odiongenyi, Corrosion Inhibitive Properties and Adsorption Behaviuor of Ethanol Extract of Piper Guinensis as a Green Corrosion Inhibitor for Mild Steel in $\mathrm{H}_{2} \mathrm{SO}_{4}$, African Journal of Pure and Applied Chemistry, 2(11), 2008, $107-115$.

[8] N. O. Eddy; E. E. Ebenso; U. J. Ibok, Adsorption, Synergistic Inhibitive Effect and Quantum Chemical Studies of Ampicillin (AMP) and Halides for the Corrosion of Mild Steel in $\mathrm{H}_{2} \mathrm{SO}_{4}$, J. Appl. Electrochem, 40, 2010, 445-456.

[9] N. O. Eddy; S. A. Odoemelam; A. J. Mbaba, Inhibition of the Corrosion of Mild Steel in $\mathrm{HCl}$ by Sparfloxacin, African Journal of Pure and Applied Chemistry, 2(12), 2008, 132-138. 
[10] E. E. Ebenso, Synergistic Effect of Halides Ions on the Corrosion Inhibition of Aluminium in $\mathrm{H}_{2} \mathrm{SO}_{4}$ using 2-acetylphenothiazine, Material Chemistry and Physics, 79, 2003, 58-70.

[11] S. A. Umoren; I. B. Obot; E. E. Ebenso; P. C. Okafor; O. Ogbobe; E. E. Oguzie, Gum Arabic as a Potential Corrosion Inhibitor for Aluminium in Alkaline Medium and its Adsorption Characteristics, Anti-Corros. Meth. Matter. 53 (5), $2006,277-282$.

[12] S. A. Umoren; E. E. Ebenso; P. C. Okafor; U. J. Ekpe; O. Ogbobe, Effect of Halide ions on the Corrosion Inhibition of Aluminium in Alkaline Medium Using Polyvinyl Alcohol, J. Appl. Polymer Sci. 103, 2007, 2810-2816.

[13] E. C. Ogoko; S. A. Odoemelam; B. I. Ita; N. O. Eddy, Adsorption and Inhibitive Properties of Clarithromycin for the Corrosion of $\mathrm{Zn}$ in 0.01 to $0.05 \mathrm{M} \mathrm{H}_{2} \mathrm{SO}_{4}$, Poertugaliae Electrochimica Acta, 27(6), 2009, 713-724.

[14] A. O. James; N. C. Oforka; O. K. Abiola, Inhibition of Acid Corrosion of Mild Steel by Pyridoxal and Pyridoxol Hydrochlorides, Int. J. Electrochem. Sci. 2, 2007, 278-284.

[15] N. O. Eddy; S. A. Odoemelam, Inhibition of the Corrosion of Mild Steel in Acidic Medium by Penicillin V Potassium, Advances in Natural and Applied Sciences, 2(3), 2008, 225-232.

[16] N. O. Eddy; B. I. Ita, QSAR, DFT and Quantum Chemical Studies on the Inhibition Potentials of Some Carbazones for the Corrosion of Mild Steel in HCl, J. Mol. Model, 2010a, DOI 10.1007/s00894-010-0731-7.

[17] N. O. Eddy; B. I. Ita, Thoeretical and Experimental Studies on the Inhibition Potentials of Aromatic Oxaldehydes for the Corrosion of Mild Steel in 0.1M HCl, J. Mol. Model, 2010b, DOI 10.1007/s00894-010-0749-x.

[18] P. C. Okafor; M. E. Ikpi; I. E. Uwah; E. E. Ebenso; U. J. Ekpe; S. A. Umeron, Inhibitory Action of Phyllanthus Amarus Extracts on the Corrosion of Mild Steel in Acidic Media, Corrosion Science, 50, 2008, 2310-2317.

[19] N. O. Eddy; A. O. Odiongenyi , Corrosion Inhibition and Adsorption Properties of Ethanol Extract of Heinsia Crinata on Mild Steel in $\mathrm{H}_{2} \mathrm{SO}_{4}$, Pigment and Resin Technology, 39(5), 2010, 288-295. 